\title{
Kamu Yönetimi Paradigmasında Afet Riski Yönetiminden Yönetişimine ${ }^{*}$
}

\author{
Dr. Öğr. Üyesi Murat Özler \\ İstanbul Üniversitesi, Siyasal Bilgiler Fakültesi, \\ murat.ozler@istanbul.edu.tr
}

\begin{abstract}
Özet
Doğal ve teknolojik kökenli olayların sonucu olarak gerçekleşen afetler, 1900 lü yılların ortalarından itibaren kentleşme olgusunda değişim ile etkilerini hem nitelik hem de nicelik olarak arttırmıştır. Küresel bazda iklim değişikliklerinin yarattı̆̆ olay ve olgularda eklenince Geleneksel Kamu yönetimi paradigmasının verileriyle bu ciddi sorun karşısında mücadele zorlaşmıştır. Hala yaşamakta olduğumuz küreselleşme sürecinin etkilemesi, Geleneksel Kamu yönetimi paradigmasının kendi içerisindeki yetersizlikleri, yönetim alanında Yeni Kamu Yönetimi Paradigması yönündeki değişim ve sorunlara ilişkin çözüm tarz ve uygulamaları ,afet yönetiminde de risk odaklı afet riski yönetimine oradan da bugünkü haliyle yönetişimine dönüşmüştür. İnsan uygarlığının ortak sorununu teşkil eden bu sorun alanı gelişmişlik düzeyi ne olursa olsun tek merkezden ve tek aktörlü müdahaleyi yetersiz kılmaktadır. Bu nedenle sorunun farkında olan ve ortak çözümün paydaşları ile güçlenmiş çok aktörlü bir afet yönetimi eski anlayışa günümüz verileriyle bir katkıdır.
\end{abstract}

Anahtar Kelimeler: Afet, Kamu Yönetimi,Yönetişim

\section{Public Management Paradigm -From Disaster Risk Management to Disaster Risk Governance}

\begin{abstract}
Disasters that are due to natural and technological reasons had greater impact on societies because of ongoing urbanization since the 1900s. Global climate changes add problems to disaster management and to combat them in the classical sense grows harder everyday. Traditional public management paradigm due to globalization and its discrepancies in itself led to disaster risk management and lastly to disaster risk governance. Since disasters are the common problems of mankind; it is impossible to interefere with them from one centered and one actor approach. Therefore; strong and multi-centered, multi -actor disaster governance is a contribution to traditional understanding of disaster governance.
\end{abstract}

\footnotetext{
${ }^{*}$ Makale Geliş/Kabul Tarihi: 24.07.18/05.03.19

Kün.: Özler, M. (2019). Kaти Yönetimi Paradigmasinda Afet Riski Yönetiminden Yönetişsimine. Kahramanmaraș Sütçü Imam Üniversitesi Sosyal Bilimler Dergisi, 16 (1), 139-150. Retrieved from http://dergipark.org.tr/ksusbd/issue/44206/474491
} 
Keywords: Disaster, Public Management, Governance

\section{Giriş}

Dünya'nın oluşumundan bu yana insan topluluklarının, doğal olayların etkileme alanına girmesiyle yaşanan afet olgusu, teknolojinin ilerlemesi ve karmaşıklaşmasıyla yaşamın odağına oturmuştur. Ulaşım ve iletişim teknolojilerinin akıl almaz nitelikte gelişmesiyle "Küresel bir köy", haline gelen Dünya, günümüzde küreselleşme olgusunu yaşar hale gelmiştir. $\mathrm{Bu}$ süreç küresel afet senaryolarını da bilimsel çalışma alanına taşımıştır.

Çok boyutlu bir süreç olan küreselleşme olgusu, (Kıvılcım, 2013; Farazmand, 1999) farklı alanlara yönelik farklı anlamlar içermektedir. İktisadi olarak ekonomik bütünleşme vurgusu yaparken, siyaset bilimi çerçevesinde bakıldığında, ulus devletin nisbi önem kaybı ve siyasal arenaya farklı aktörlerin katılımıyla tek egemenliğinin sonu olarak zikredilmektedir. Ekonomik ve siyasal boyutların yanında küresel iklim değişikliklerinin hissedilir olmasıyla günümüzde küreselleşme kavramı, afet olgusuna da küresellik boyutu eklemiştir. Uzmanların belirttiğine göre, bu boyut yakın gelecekte tüm küreyi ciddi şekilde tehdit eder niteliğe bürünecektir (Erkan, 2010:37; Tuna, 2000). Dolayısıyla küresel bir tehdit karşısında ortak mücadele ve önlemler alınması kaçınılmaz bir durum olarak gözükmektedir (Şahin, 2016; Köse, 2018).

Küreselleşme olgusu her ne kadar çağımız örgütlenmesi olan ulus devletin tek aktörlüğüne son vererek yönetişim yaklaşımını teşvik etmekteyse de, Devletin temel görevi olan vatandaşlarının can ve mal güvenliğini her türlü tehdit ve tehlikelere karşı koruma yani güvenlik ve savunma fonksiyonlarını*zayıflatma yönünde etkili olamamıştır. Yani Ulusal düzeydeki örneklerde yaygın olarak görünen ve uluslararası düzeyde ise örnekleri bulunan özel güvenlik ve özel askeri kuvvetler (Mcfate, 2015) uygulamaları dikkate değer olmakla beraber, bu temel kuralı bozacak nitelikte değildir.

Dün olduğu gibi bugünde kamu güvenliği, kamu düzeni, milli güvenliği korumak ve devamını sağlamak ve bu alanlara ilişkin kamu hizmetlerinin kurulması ve etkin bir şekilde sürdürülmesi devletin asli vazifesi olduğu kadar varlık koşuludur. Dolayısıyla küreselleşmenin çok boyutlu süreci ile ulus devletin öneminde ki nisbi azalış, bu alanlara ilişkin görevi tasfiye etmek zayıflatmak yerine daha da önemli kılmıştır. 1980'lerin başından bu yana kamu yönetimi alanındaki kapsamlı değişime alt yapı oluşturan küreselleşme olgusu, devletin fonksiyonlarını ve rolünü esaslı biçimde etkilerken, afet olgusuna yaklaşım da şüphesiz bu durumdan etkilenmiştir.

Devlet cihazının kuruluş ve işleyişindeki anlayış değişikliği ile bir yanda minimal devlet unsurunu zorlayan değişimler diğer yanda ise küçülen 
ama daha etkin, verimli işleyen bir yap1 afet olgusuna bakışı yenilemiştir (Afet Yönetiminde Etkinlik, 2014).

\section{Afet Olgusu ve Afet Yönetim Döngüsü}

\subsection{Afet Olgusu ve Temel Kavramlar}

Afet: insan toplumunu veya yerleşim yerleri için maddi ve manevi zararlar oluşturan ve normal yaşam düzenini durduran veya kesintiye uğratan doğal ya da teknolojik kökenli olayların sonuçlarıdır (Ergünay, 2002:3; Kadıŏlu, 2011:36). Afet olgusuna unsurları üzerinden bakacak olursak, etkili olduğu alan itibariyle insan yerleşim alanı veya yerleşim alanını yakından fiziki veya işlevsel etkileme potansiyeli taşıan sahalarda etki yaratması ve bu etkinin zarar kabul edilecek düzeyde olması gerekir. Zarar, maddi, manevi veya psikolojik olabilir. Ekonomik, sosyal, kültürel, siyasal, sosyolojik düzeyleri bu boyutta etkileyen tüm zararlar bu niteliktedir. $\mathrm{Bu}$ etkileme insan toplumlarının normal yaşam düzenini belirli bir süre kesintiye uğratarak bozan ve işleyişi engelleyen nitelikte olabileceği gibi, tümüyle ortadan kaldırarak engelleyen düzeyde de olabilir. Dolayısıyla afetlere yol açan, onların oluşmasına neden olan şey doğal ya da teknolojik orjinli, normal yaşam düzenini sekteye uğratan olaylardır.

Afetlere yol açan olayların sınıflandırılması doğal, çevresel, küresel, biolojik, meterolojik, kimyasal, nükleer, sosyal, siyasal, teknolojik gibi birçok şekilde olabilir. Ancak bu dağınık ve çeşitli mevcudu iki ana grupta toplamak mümkündür. Bu siniflandırmada kriter afete neden olan orjinin kaynaklandığı durumdur. Buna göre, doğal ve teknolojik nitelikli olaylar bir grup altında toplanabilecektir. Doğal olaylar Dünyanın varoluşundan bu yana işleyişi çerçevesinde neden sonuç ilişkilerine bağlı olarak gerçekleşen olaylardır. Bunlar: depremler, seller ve su baskınları, toprak kaymaları, çığlar, volkanik patlamalar, yangınlar, kuraklık, kıtlık gibi doğal olaylardır ve diğer grup ise, nükleer, biolojik, kimyasal kazalar, endüstriyel kazalar, terör, savaş, göç gibi teknolojik nitelikli olaylardır. Bunlar doğal nedenler dışındaki nedenlerle oluşmakta, yani insanlığın doğal yaşam karşısında ortaya koyduğu oluşturduğu bilgi uygulaması kökenlidir.

Doğal olsun, teknolojik nitelikli olsun afet yaratan olaylar ikincil tehlike ve zararlar oluşturan olaylara da neden olmaktadır. Çoklu olay yaklaşımı çerçevesinde bakıldığında en kapsayıcı ve çarpıcı örnek depremdir. Büyüklüğü ve şiddeti büyük bir deprem yerleşim yerlerinde can kayıpları ve yaralanmalara neden olduğu gibi, büyük yıkımlar, alt yapının tahribi ,ulaşım ve enerji nakil hatlarının ciddi zarar görmesi, barajların ve setlerin yıkılması seller, toprak kaymaları patlama ve yangınlar, hava kirliliği, kimyasal kazalar ve zehirlenmelere bağlı olarak bir çok ikincil afet odağına neden olabilmektedir (Kadığlu, 2011:25). Bu duruma güncel bir örnek: 11.3.2011'de Japonya Fukuşima depremi: Tsunami, yıkım, nükleer 
sızıntı, zehirlenme, toprak tahribi ve yangınlara neden olmuştur." (Fukuşhimaontheqlobe.com/the-earthquake-and-the-nuclearacciedent)(Erişim 28.5.2018).

Günümüzde her ne kadar bu iki grup kümesine girse de, Küresel afetler diye nitelediğimiz bir grubu ayrımlamak da zorunlu olmuştur. Belki de Küresel nitelik kazanmış afetler isimlendirmesi daha uygun olacaktır. Doğal olsun teknolojik kaynaklı olsun bir olayın küresel nitelik kazanması, etkisi ve yaygınlığı ile ilgili bir durumdur. Bu çerçevede salgınlar, ciddi düzeylere varan kirlilik, küresel iklim değişiklikleri, kimyasal ve radyoaktif serpintiler örnek verilebilir.

İnsan toplumunu ve yaşam düzenini tehdit eden doğal ve teknolojik nitelikli olayların tümü aynı derece ve yoğunlukta tehlike yaratmaz. Her olayın bünyesinde farklı tehlike potansiyeli vardır. Tehlike, gerçekleşmesi potansiyel olarak mümkün olan ve gerçekleşmesi halinde zarar yaratabilecek nitelikteki bir kavrama işaret eder (Özkılıç, 2014: 14). Tehlikenin derecesine vurgu yapan, oluşma olasılığını içeren tehdit (Kadıŏlu, 2011: 23) kavramı ise, yakın tehlike anlamını deyimlemektedir.

Risk kavramını (Kadığlu, 2011: 22) ise hem tehlike hem de tehdit kavramlarını içeren bir kavram olarak, öncesinde tehlike analizi yapılmış bir olay için olabilirlik olasılığı olarak ifade edebiliriz. Bu yönüyle istatistiksel bir vurgu içerirken, çoğu zaman potansiyel veya yakın zarar oluşturma seviyesini vurgular.

Potansiyel veya yakın zararlar her zaman önceden saptanamayabilir. Bazı durumlarda daha önceden hiç yaşanmamış veya üzerinde durulmamış bir olay ortaya çıkarak zararlar yaratabilir. Bu tip durumlar beklenmedik olay olarak ifade edilebilir ve olaya yakındaki birimlerin anlık acil durum müdahalesi çoğu zaman yeterli olabilmektedir.

\subsection{Afet Riski Yönetim Döngüsü}

Afet risk yönetimi en genel şekilde tanımlanırsa, insan toplumunu ve düzenini yerel, bölgesel, ulusal ve küresel ölçekte tehdit eden zarar yaratabilecek tehlikelerin önceden belirlenmesi, mümkünse tehlikenin tümden ortadan kaldırılması, değilse zararın azaltılmasına yönelik planlama ve örgütleme unsurları ile önlem alınması, acil müdahale ve uygulamaların ifas1, oluşabilecek ikincil tehdit ve tehlikelerin kontrolü ve iyileştirme çalışmalarının süratle hayata geçirilmesine yönelik bir dizi faaliyetin planlanması, örgütlenmesi, koordinasyonu, motivasyonu ve her aşamada denetimini içeren bir süreçtir (Kadığlu, 2011:48).

Afet risk yönetiminin unsurları aslında döngüsel ve birbirini takip eden ve yeniden üreterek tamamlayan bir süreçtir (Yılmaz, 2003:39). 
Bütüncül olarak ve döngüsel süreci ayrıntıya indirgemeden üç safha olarak belirtmek mümkündür (Kadığlu ve Özdamar, 2008:9).

a- Afet öncesi: (Risk Yönetimi): Afet döngüsündeki ilk halka tehlike oluşturabilecek olayların bilimsel esaslara uygun olarak planlı ve programlı bir şekilde saptanmasıdır (Ergünay, 2002: 8). Yerel ölçekten ulusal bütüne uzanan düzeyde tehlike oluşturabilecek durumların bölgesel ve ulusal bütün dışındaki rabıtaları da göz önünde tutularak ortaya konması gerekir. Her bir duruma ilişkin tehlike analizi yapılarak, tehdit özelliği vurgulanarak risk yönetim sürecinin özelliklerine uygun ortaya konulmalıdır. Yani düşük, orta, yüksek risk öncelikleri olayın sonuçları tahmin edilerek belirlenmelidir (Kadığlu, 2011:57).

Tehlike içeren olayların gerek oluş sıklı̆̆ı gerekse sonuçları itibariyle olabilecek zararın büyüklüğü bize bu konuda tasnif yapma imkanı sunmaktadır (Özkılıç, 2014:49). Yani Risk Matrisi (Kadıŏlu, 2011: 76), risk azaltma için yapılabilecek plan önceliklerini ortaya koyabilecektir. Buna göre öncelikli olarak yakın zamanda ve en çok zarar oluşturma potansiyeline sahip düzeyden başlayarak riskin ya tümden ortadan kaldırılması ya da mümkün olduğunca azaltılması yönünde faaliyetlerin planlanmas1, örgütlenmesi, bu konulara ilişkin eğitim ve koordinasyonun motivasyon unsurlarıla takviye edilerek uygulamaların her aşamada denetlenmesi gerekir. $\mathrm{Bu}$ aşamada tedarik zincir hattı, alet edevat malzeme kaynak stoklanması, iletişim ve ulaşım kanallarının her daim açık tutulmasına ilişkin örgütsel yapının hazır tutulması son derece önemlidir.

b- Afet anı (Kriz Yönetimi): Bu safha olayın vuku bulduğu ve sıcaklığının devam ettiği zaman dilimini deyimler (Kadığlu, 2011: 163). Her bir olay için farklı süreler içerir Bundan dolayı birinci safhada afet öncesinde hazırlık çalışma ve faaliyetlerinin eksiksiz yapılmış olması bu safhadaki başarıyı etkileyecektir. Yani her bir olayın özelliğine göre yapılmış planlar ve kurulmuş örgütler olağan işleyişini bırakarak kriz düzeyli devreye girecek, can ve mal kurtarma çalışmalarını eksiksiz yerine getirecektir. Bu evrede geçici nitelikte oluşturulacak tuvalet, barınak, sağlık, seyyar hastane, enerji üretim gibi iyileştirme faaliyetleri de söz konusu olacaktır. Bunların yanında bölgenin tahliyesini sağlayacak ve tedarik zincirini oluşturacak kapasite son derece hassas öneme sahiptir.

c- Afet sonrası (iyileştirme): Bu safha afetin sıcak etkisinin bittiği veya soğumaya başladığı bir evre olarak durmuş veya kesintiye uğramış yaşamın normalleşmesi ve olağan hale dönmesi için yapılacak tüm faaliyetleri kapsamaktadır. Buna göre öncelikle geçici olandan kalıcıya barınma, sağl1k, alt yapı, beslenme, enerji temini ve tüm bir normal yaşamın akışı için gerekli olan unsurların kurulmasını içerir. Yaşanmış olayın özelliğine göre süre içerir. Ancak ne olursa olsun bu süre optimum olmalı ve olağanüstüyü olağanlaştırmamalıdır. 
Afet riski yönetim döngüsü sürecinin her bir halkası birbirini tamamlar nitelikte, bir bütünün parçasını oluşturur. Dolayısıyla bir unsurda oluşabilecek eksiklik ve aksaklık tüm bir süreçte olumsuzluk oluşturarak, sistemi olumsuz yönde etkileyecektir.

\section{Geleneksel Kamu Yönetimi Paradigmasından Yeni Kamu Yönetimi Paradigmasına - Afet Yönetimi}

Klasik anlayış çerçevesinden hareketle ifade etmeye çalışırsak, kamu yönetimi: Devletin hukuki yetkileri olan yasama, yargılama ve belirli bir ölçüde de yürütme yetkisinin dışında kalan ve yasalarca belirlenen bir alanda, kamu politikalarının ayrıntılı icrasına (Wilson, 1887) ilişkin olarak planlama, örgütleme, koordinasyon, motivasyon ve denetim işlevlerini yerini getiren örgütler ve usuller bütünüdür. Kendine özgü örgütler vasitasıyla yasalarla belirlenmiş hukuksal rejim içerisinde, bütünün çıkarına yönelik olarak mal ve hizmet sunan veya sunulmasını sağlayacak ortamı üreten, bu amaçla örgütleri oluşturan ve işleten yapıdır.

Oluştuğu yüzyıldan bu yana ciddi bir değişiklik geçirmeden varlığını sürdüren Geleneksel Kamu Yönetimi Anlayışı,1980'li yıllardan itibaren iletişim ulaşım teknolojilerinin büyük ölçüde gelişmesinin sağladığı imkanlarla ama asıl ekonomik ve mali krizlerin zorlaması ve küresel örgütlerin etkisiyle yaygınlaşan yeni bir paradigmaya bırakmaya başlamıştır. Dünya çapında gelişmiş ülkelerin bir çoğunda kamu yönetimi alanında kapsamlı ve yoğun değişimler Geleneksel Kamu Yönetimi Anlayışının Yüzyıllık egemenliğini Yeni Kamu Yönetimi Paradigması (Hood, 1991) lehine bırakmaya başlamasıyla sonuçlanmıştır (Nunberg 1992). Bu gelişme sadece 1980'lerden sonra ortaya çıkan eşzamanlı değişimlerin değil,aynı zamanda geleneksel kamu yönetimi paradigmasının yetersizliklerinin de bir sonucudur.

Geleneksel Kamu Yönetimi Paradigmasının üzerine kurulu olduğu temel unsurlar: siyaset ve idare ayrımı, kamu ve özel kesim farklılığı ve bürokratik örgütlenme modelidir. Bu çerçevede en uygun örgütsel yapı olarak katı hiyerarşik merkeziyetçi yapı öngörülmüştür. Diğer yandan Kapalı sistem yaklaşımının benimsenmesi nedeniyle vatandaş katılımı da dar olmuştur. Sonuçları göz ardı eden, girdi ve sürece odaklı yaklaşım, İkinci Dünya Savaşı ertesi Keynesyen ekonomik politikaların etkisiyle kamu hizmetlerinin kurulması, işletilmesi ve devasa büyüyen ve hantallaşan devlet örgütüne dönüşmüştür (Wilson, 1887).

Yeni Kamu Yönetimi Paradigması'nın minimal devlet anlayışı ve işletme yönetim tekniklerinin uygulanmasını da içermesi ile uygulamada adem-i merkeziyetçi, yatay, hiyerarşik olmayan hantallıktan uzak, sonuçlara odaklı, hesap verme sorumluluğu içeren anlayışı ve uygulamaları, geleneksel anlayışın eksiklik ve yetersizliklerine cevap olmuştur (Biliç, 2008). 
Geleneksel anlayışın katı, hiyerarşik merkeziyetçi yapıyı temel alması ve afet gibi her an yeni olay ve olgularla değişebilecek durumlara uygun düşmemektedir. Bu tarz yapılanmanın gecikme ve sağlıklı analiz yapamama potansiyeli de fazladır. Buna bağlı olarak böyle bir yapılanmanın geçerli olduğu yapılarda alt birimlerin takdir yetkisinin azaldığı, kararların tek merkezden alınarak alt birimlere kadar silsile yoluyla ulaştığı hiyerarşi ilkesinin gereğidir. Diğer yandan merkezi yapının, hizmetin planlamasından kurulmasına, yönetiminden icrasına kadar süreçlerin belirleyicisi olması büyük, kapsamlı ve süreklilik arz ederek değişiklikler içeren olaylarda süratli,isabetli ve etkin önlem almayı imkansız kılmaktadır.2005 Yılı gibi Yakın bir tarihte Amerika Birleşik Devletlerinde yaşanan Katrina Kasırgası bu duruma çok güzel bir örnektir. Nitekim FEMA (Federal Emergency Management Agency - Federal Acil Durum Yönetim Kurumu) bu olaydan sonra afet-risk yönetimi yönünde çok ciddi idari ve hukuksal değişiklikler yaşamıştır (Department of Homeland Security, 2006). Özellikle ilk 24 saatlik zaman diliminde, olayın mahiyeti ve yarattığı neticeler hakkında sağlıklı bilgi almak bile mümkün olamamakta, üç güne kadar istenilen müdahale imkanı yaratmak ise zordur. Hiç şüphe yok ki bundan sonraki süre içerisinde afete karşı başarıda devletin gücü ile orantılı olacaktır.(Ekşi,2016:30)Ancak bu güç, afet esnasında kullanacağı olanakları olağan dönemde etkin bir şekilde kurmuş ve kurumsallaştırmış yapılar için geçerlidir. Olağan dönemde kurulmuş ve etkin işleyen yapıların afet gibi olağandışı bir durumda kullanılma işlevi üstlenmesi başarıyı olumlu etkileyecektir. Olağan dönemde ortada böyle bir yapı yoksa veya mevcut olup da olağan dönemde bile sağlıklı işlemiyorsa afet anında olumlu bir işlev beklemek yanlış olacaktır.

Afetler olağandışı, olağanüstü durumları deyimler. Dolayısıyla böyle durumlarda girdi ve süreç odaklı yaklaşımlar her zaman bizi istenilen sonuçlara götürmez. Sonuçlara ulaşmanın hukuk kurallarına, prosedürlere uygun şekilde olması gerekir. Ancak bu şekilde mümkün olamıyorsa istisnai olmak koşuluyla kuralların esnetilmesi gereklidir. Ve bu hizmete en yakın ve durumu bizzat gören birimlerce takdir edilmelidir. Sonuca odaklılık amacı gerçekleştirmeye yönelmelidir. Dolayısıyla Anayasal siyasi afetlerde Anayasalar bu gibi durumlarda takdir yetkisinin genişleyeceğini kural altına almışlardır (Özler,2016).

Diğer yandan esneklikten yoksun büyük ölçekli yapılarla hızlı ve etkin müdahale yapılamadığı gibi, koordinasyon da sağlanamaz. Hatta sistemin öngördüğü hiyerarşi ilkesi bile bozularak etkin işlemez. Bu durum bürokratik başarısızlık olarak adlandırılır. Dolayısıyla afetlerde müdahale yatay, esnek ve ufak birimler ile sağlanmalıdır.

Yeni Kamu Yönetimi Paradigmasıly Devletin işlevlerinde öngörülen bu kapsamlı değişim afet olgusuna yönelik anlayışı da değiştirmiştir. Geleneksel Kamu Yönetiminin afet yönetiminde müdahale ve kriz yönetimine odaklı anlayışı, Yeni Paradigma çerçevesinde risk 
yönetimine ağırlık vererek afet döngüsünü bütüncül olarak ele almaya ve tek aktörlü süreci çok aktörlü hale yani, yönetimden yönetişime evrimlemiştir. Nitekim bütünleşik afet yönetimi kavramının içeriğini yönetişim yaklaşımını içerir şekilde anlamak isabetli olacaktır (Kadığlu, 2008:9). Yani farklı sektör ve kesimlerin ortak katılımını içeren bir anlayış olarak (Keleş, 2013:63).

4.Yeni Kamu Yönetimi Paradigması - Afet Yönetiminden Yönetişimine ve Afete Dirençli Toplum

Yeni Kamu Yönetimi Paradigması'nın günümüzde ulaştı̆̆ yönetişim aşaması (Coşkun, 2008), devletin, kamu idarelerinin tek başına güç ve yetkiyi kullanma anlayışını sivil toplum, özel sektör, birey, gönüllü kuruluşlar, meslek örgütleri, üniversiteler gibi aktörlerle paylaşarak (Nohutçu ve Balc1: 2008) uzlaşma ve güç birliği temelinde çözme girişimidir (Keleş, 2013:67). Afet olgusu karşısında bireyi ve sivil toplumu dışlayan anlayışların tek merkez üzerinden tüm sorunlara çare üretmeleri günümüz Dünyasında son derece zordur. Bu nedenle tüm güç unsuru kesimlerin ortak hedef doğrultusunda kararların planlanmasından uygulanmasına kadar devam eden süreçte koordinasyon içerisinde paydaş olması zorunludur. Toplum desteği olmadan siyasal, fiziki, ekonomik düzenin yanında ahlaki ve sosyal düzeni de tahrip eden büyük afetlerle etkin mücadele yapılamayacağı örneklerle sabittir. Çünkü devlet ne kadar gelişmiş olursa olsun büyük afetler karşısında anlık olarak profesyonel cevap veremez. Hatta olay türlerine göre farklılık içerse de ilk 24 saatlik zaman dilimi son derece önem taşımaktadır. $\mathrm{Bu}$ dilime ilişkin toplumsal refleks, nitelik olarak afete dirençli olma özelliğini kazanmış toplumca verilebilir. Bu sayede can ve mal kayıpları en aza indirilerek afetin neden olduğu sonuçlar hafifletilebilecektir.

Geçmiş yüzyıllık sürece baktığımızda afet niteliğindeki olguların sayısal olarak ve zararlarının da yüzlerce kat arttı̆̆ görülecektir. Kırdan kente göç olgusu ve nüfusun gelişigüzel kentlerde temerküzüne Şu anda bile etkilerini sıkça hissettiğimiz küresel iklim değişiklileri de eklenince bu artışı önümüzdeki on yıllarda daha da körüklenecektir. Nitekim bu belirlemelerden hareketle Birleşmiş Milletler, gelişmekte olan ülkelerin önündeki en büyük kalkınma engelinin afetler olduğunu vurgulayarak uluslararası platformda konuya ilişkin faaliyetlerde bulunmuştur (Stromberg, 2007).

Birleşmiş Milletlerin 1990-2000 yılları arasındaki on y1lı Uluslararası Doğal afetlerin on yılı olarak kabulü, 1992 Rio Zirvesi, 1994 Yokohama Deklarasyonu ve Eylem Planı, afet zararlarının azaltılmasında 2005-2015 Hyogo Çerçeve Eylem planı, Hyogo Çerçevesi üzerine temellendirilen afet kayıp ve risklerinin azaltılmasına odaklanan 14-18 Mart 2015 Sendai Çerçevesi, 23-24 Mayıs 2016 Dünya İnsani Zirvesi, 4 Kasım 2016 da yürürlüğe giren iklim değişikliği rejiminin çerçevesini oluşturan Paris Anlaşması örnek verilebilir. Dünyada ve ülkemizde müdahale merkezli afet yönetiminden risk yönetimine ağırlık veren anlayış ve uygulamaya 
geçiş, afet tehlikesi karşısında afet oluşmadan zararları önleme veya azaltma ekonomik, fiziki, sosyal, siyasal tüm yönler itibariyle daha ekonomik ve rasyoneldir.

Toplum destekli afet-risk yönetimi, Yeni Kamu Yönetimi Paradigmasının yönetişim anlayışını vurgular. Yani devletin bu sahada tek belirleyici olma tekelinin farklı aktörlerce paylaşılması, yetki ve sorumlulukların merkezden yerele ve merkez dışındaki belediyeler, aile, gönüllü kuruluşlar, özel sektör, vakıf ve dernekler gibi unsurlara aktarılarak yerel ve merkez dış1 kapasitenin güçlendirilmesidir. Nitekim Küresel bir örgüt olan Dünya Bankasının 1990'lı y1llarda afet zararlarının azaltılmasında bilim ve teknolojinin kullanılması hedefi, yönetişim yaklaşımının önerilmesi suretiyle yerel ve merkez dışı unsurların kapasitelerinin desteklenerek güçlendirilmesi, toplumla beraber mücadele politikaları bu merkezdedir (Coşkun, 2008).

Risk yönetiminin etkin ve verimli uygulanabilmesi demokratik ülkelerde toplumsal kültür desteği olmadan son derece zordur. Afetler tümüyle önlenemese de bireylerin veya toplumsal küçük birimlerin eğitime dayalı edindikleri bilgileri uygulayarak alabilecekleri önlemler can ve mal kayıplarını önemli ölçüde azaltabilecektir. Diğer yandan kamunun risk azaltma faaliyetleri hakkında bilgi sahibi olan yerel, bu faaliyetleri denetleyerek politikaların paydaşı olacaktır. Böylece bu sosyal sermaye katkısı kamu yönetiminin verimli ve etkili olmasını sağlayacaktır.

Afet-risk yönetimi çerçevesinde toplumsal destek, toplum kültürünün dönüşümü, vatandaşlık bilinci ve bunu destekleyen siyasal, sosyal ve hukuksal ortam ile mümkün olabilmektedir. Toplum desteğinden amaç kendi kendine yeterli ve bütüncül olarak yapılan faaliyetleri koordinasyon içerisinde destekleme hedefine odaklanır. Eğitim ve diğer vasitalarla yapilan faaliyetlerin yasalarla desteklenmesi, sivil toplum, yerel yönetimler ve halk ilişkisinin kurumsallaşması yönetişim yaklaşımına işlevsellik kazandıracaktır.

Farklı aktörlerin güç birliğini deyimleyen yönetişim yaklaşımı, afet mücadelesinde yerel yönetimlere özel bir işlev yüklemektedir. Çünkü kentsel afetlerde risk yönetimini hayata geçiren işlevsel birimler yerel yönetimlerdir (Kentleşme Şurası, 2009). Toplum destekli yerel yönetimler kapasiteyi arttırarak yönetişim modelinin işlevselliğini arttıracaktır.

\section{Sonuç}

Dünyanın varoluşundan bu yana insan toplumlarının doğal ve teknolojik kaynaklı olaylardan etkilendiği bir vakıadır. Kentleşmenin ve toplu halde yaşamanın artması, teknolojinin çeşitlenerek karmaşıklaşması afetlere neden olayların da hem nitelik hem de nicelik bakımından artmasına 
neden olmuştur. Geriye dönük bakıldığında ki yüz yıllık süreç afetleri sayısal ve nitelik bakımından yüzlerce kat çoğaltmış ve artan ve karmaşıklaşan teknolojiye bağlı olarak da iklim değişikliklerini de tetikleyerek yaygınlık ve yoğunluk kazanmasına ve küresel düzeyde de afetler kategorisi oluşmasına neden olmuştur.

Nitelik ve nicelik bakımından artan ve çeşitlenen büyük ölçekli afetler karşısında merkezi ve hiyerarşik yapılarla afet oluştuktan sonra müdahale ve iyileştirmeye odaklı yönetim yaklaşımları yetersiz kalmıştır. Ancak geçtiğimiz on yillarda iletişim ve ulaşım teknolojilerindeki ciddi boyutlardaki ilerleme ve bununla eşzamanlı nedenlere bağlı olaylar yönetim anlayışında gelenekselden yeniye, paradigma değişimini mümkün kılmıştır. Kamu yönetimi alanında paradigma değişimi tüm alanları etkilediği gibi afet yönetimi alanında da ciddi değişimlerin belirleyicisi olmuştur. Paradigma değişiminin küreselleşme süreci ve onun taşıyıcısı olan küresel örgütler vasıtasıyla yaygınlık ve yoğunluk kazanması ile yönetimden yönetişime evrilen anlayış ve uygulama gelecekte farklı dönüşümlerin nedenini teşkil edecektir.

\section{Kaynakça}

Afet Yönetiminde Etkinlik. (2014). Onuncu Kalkınma Plan1 2014-2018. Özel İhtisas Komisyonu Paporu, Ankara.

Afet Zararlarını Azaltmanın Temel ilkeleri. (2008). (Ed.) Mikdat Kadığlu, Emin Özdamar, JIJA Türkiye Ofisi, Yayın no: 2, Ankara.

Afete Hazırlık ve Afet Yönetimi. (2002). (Hzl.) Oktay Ergünay. Türkiye Kızılay Derneği Genel Müdürlüğü Afet Operasyon Merkezi, Ankara.

Bilgiç, V. (2008). Yeni Kamu Yönetimi Anlayışı. Kamu Yönetiminde Çağdaş Yaklaşımlar, (Ed.) Asım Balcı, Ahmet Nohutçu vd. 2.b., Ankara. ss.27-47.

Coşkun, B. (2008). Kamu Yönetiminde Yönetişim Yaklaşımı. Kamu Yönetiminde Çağdaş Yaklaşımlar, (Ed.) Asım Balcı, Ahmet Nohutçu vd. 2.b., Ankara. ss.67-83.

Department of Homeland Securıty, Office of İnspector General. (2006). A Performance Review of FEMA 's Disaster Managment Activities in Response to Hurricane Katrina. Office of Inspections and Special Reviews. (www.oig.dhs.gov.). (Erişim,28.5.2018).

Ekşi, A. (2016). Kamu Yönetiminde Değişimin Afet Yönetimi Uygulama Alanına Etkileri. Hastane Öncesi Dergisi, 1(1): 27-41. 
Erkan E. A. (2010). Afet Yönetiminde Risk Azaltma ve Türkiye'de Yaşanan Sorunlar, DPT Uzmanlık Tezleri, Ankara.

Farazmand, A. (1999). Globalization and Public Administration, Public Administration Review, 59(6): 509-522.

Hood, C. (1991). A Public Mangement for All Seasons. Public Administration, C.69, ss.3-19.

Hüseyin C. ve Volkan S. B. (2011). Risk Değerlendirme Tablosu Yöntemi ile Risk Analizi: Bir Uygulama. International Journal of Engineering Research and Development, 3(2).

Kadıoğlu, M. (2008). Modern Bütünleşik Afet Yönetiminin Temel İlkeleri, Afet Zararlarını Azaltmanın Temel İlkeleri. JIJA, Ankara: Türkiye Ofisi Yayınları No:2 ss.1-34.

Kadıŏlu, M. (2011). Afet Yönetimi Beklenilmeyeni Beklemek, En Kötüsünü Yönetmek. İstanbul: T.C. Marmara Belediyeler Birliği Yayını.

Keleş, R. (2013). Yönetişim Kavramına Eleştirel Bir Yaklaşım. Yönetişim, (Ed.) M.A. Çukurçayır ve H.T. Eroğlu. Konya: Çizgi Kitabevi, ss.57-70.

Kentleşme Şurası. (2009). Afetlere Hazırlık ve Kentsel Risk Yönetimi Komisyonu. Ankara.

Kıvılcım, F. (2013). Küreselleşme Kavramı ve Küreselleşme Sürecinin Gelişmekte Olan Ülke Türkiye Açısından Değerlendirilmesi. Sosyal ve Beşeri Bilimler Dergisi, 5(1).

Köse, İ. (2018) İklim Değişikliği Müzakereleri: Türkiye'nin Paris Antlaşması'nı İmza Süreci. (dergipark,gov.tr/esam/issue/328119/329348 (erişim 6.5.2018).

Macfate, S. (2015). The Modern Mercenary (Hardcover) Oxford Univercity Press, USA.

Nunberg, B. (1992). Managing the Civil Service: What LDC Can Learn From Devoloped Country Reform, Washington D.C.: The World Bank. 
Özkılıç, Ö. (2014). Risk Değerlendirmesi Atex Direktifleri-Patlayıcı Ortamlar Büyük Endüstriyel Kazaların Önlenmesi ve Etkilerinin Azaltılması-Kantitatif Risk Değerlendirme. Ankara: Türkiye İşveren Sendikaları Konfederasyonu Yayını.

Özler, M. (2016). 1982 Türkiye Cumhuriyeti Anayasası'na Göre Olağanüstünün Olağanlaşması ve Kriz Hukuku, İstanbul: Filiz Kitabevi.

Stramberg, David. (2007). Natural Disasters, Economic Development and Humanitarian Aid, Journal of Economic Perspectives, vol. 21, no. 3, p. $199-222$.

Şahin, Uysal Ö. (2016). Kyoto Protokolü ve Kopenhag Mutabakatı'nın Karşılaştırmalı Analizi, dergipark.gov.tr/download/articleFile/358018 (erişim 8.5.2018).

Toplumsal Kapasitenin Geliştirilmesi ve Toplum Eğitimleri. Haziran, (2014). www.güvenliyaşam.org/wpcontent/uploads/2016/02/eğitim.pdf (erişim 24.3.2018).

Tuna, M. (2000). Çevresel Sorunların Küreselleşmesi. Muğla Üniversitesi Sosyal Bilimler Enstitüsü Dergisi, Sayı2.

Wilson, W. (1887). The Study of Administration. Political Science Quarterly, 2(2):197-222.

Yılmaz, A. (2003). Türk Kamu Yönetiminin Sorun Alanlarından Biri Olarak Afet Yönetimi. Ankara: Peğem A Yayınc1lık. 